\title{
Assessing Children's Executive Function: BADS-C Validity
}

\author{
Jessica Fish ${ }^{1 \dagger}$ and F. Colin Wilson ${ }^{2 *+}$ \\ 1 Institute of Health and Wellbeing, College of Medical, Veterinary and Life Sciences, University of Glasgow, Glasgow, United \\ Kingdom, ${ }^{2}$ Regional Acquired Brain Injury Unit, Musgrave Park Hospital, Belfast Health and Social Care Trust, Belfast, \\ United Kingdom
}

\section{OPEN ACCESS}

Edited by:

Daniela Smirni,

University of Palermo, Italy

Reviewed by:

Georgina Warner,

Uppsala University, Sweden

Adriana Lis,

University of Padua, Italy

*Correspondence:

F. Colin Wilson

colin.wilson@belfasttrust.hscni.net

tORCID:

Jessica Fish

orcid.org/0000-0002-9337-1489

F. Colin Wilson

orcid.org/0000-0002-4290-2833

Specialty section:

This article was submitted to

Neuropsychology,

a section of the journal

Frontiers in Psychology

Received: 05 November 2020

Accepted: 11 January 2021

Published: 19 February 2021

Citation:

Fish $\mathrm{J}$ and Wilson FC (2021) Assessing Children's Executive

Function: BADS-C Validity.

Front. Psychol. 12:626291. doi: 10.3389/fpsyg.2021.626291
Objectives: To investigate the external and ecological validity of a standardized test of children's executive functioning (EF), the Behavioral Assessment of the Dysexecutive Syndrome for Children (BADS-C).

Background: There are few standardized measures for assessing executive functions in children, and the evidence for the validity of most measures is currently limited.

Method: A normative sample of 256 children and adolescents from age 8-16 years completed the BADS-C, and a parent or teacher completed rating scales of the child's everyday problems related to EF (Children's version of the Dysexecutive Questionnaire; DEX-C) and Strengths and Difficulties Questionnaire (SDQ), a commonly used measure of emotional, social, cognitive, and behavioral problems.

Results: Exploratory factor analyses yielded a two-factor structure to the BADS-C, indicative of monitoring and abstract reasoning processes, and a three-factor structure to the DEX-C, reflecting behavioral, and cognitive components of the dysexecutive syndrome as well as emotional responsiveness. Regression analyses showed significant relationships between BADS-C scores and everyday functioning as reported on the DEX and SDQ. Furthermore, there were significant differences in BADS-C scores between those children in the upper and lower quartiles on the SDQ.

Conclusion: Results provide tentative evidence of BADS-C and DEX-C construct, convergent and predictive validity.

Keywords: executive function, assessment, ecological validity, child development, cognitive function

\section{INTRODUCTION}

The term "executive functioning" (EF) refers to the processes involved in the coordination of more basic cognitive functions, and hence produce organized, goal-directed, behavior (Welsh and Pennington, 1988; Alvarez and Emory, 2006). It is an overarching term which includes cognitive functions such as planning, problem solving, fluency, attentional control, working memory, inhibition as well as cognitive flexibility (Nyongesa et al., 2019) although precise consensus remains elusive. Notwithstanding EF has an important role in mediating the development of socioemotional and educational attainments (Riggs et al., 2006) and is known to be a predictor of future 
life outcomes including productivity (Diamond, 2013). Impairments of EF have been reported in many pediatric clinical groups including Attention Deficit/Hyperactivity Disorder (Barkley, 1997; Willcutt et al., 2005), Pervasive Developmental Disorders such as Autism (Hill, 2004; Robinson et al., 2009), Syndromes associated with Intellectual Disability such as Fragile X (Cornish et al., 2004), and Down's Syndrome (Lanfranchi et al., 2010), Epilepsy (Parrish et al., 2007) as well as Traumatic and other Acquired Brain Injuries (Slomine et al., 2002; Chevignard et al., 2010). Such impairments can have detrimental effects on behavior, social development and educational outcomes (Biederman et al., 2004; Tonks et al., 2011), and consequently the identification of problems with EF is of great clinical importance.

The most influential models of EF are those derived from adult neuropsychology, specifically studies of patients with circumscribed lesions to areas of prefrontal cortex. It is known that such patients can display a variety of striking changes in cognition, behavior and perceived "personality." Stuss and Benson (1984) for example, specified six common features as: the separation of action from knowledge, difficulty in sequencing language and behavior, problems in forming and shifting cognitive "set," reduced resistance to interference, impaired monitoring of behavior, and an acquired attitude of unconcern, unawareness or apathy. Baddeley and Wilson (1988) employed the term "dysexecutive syndrome" to represent this cluster of impairments, due to the role of the central executive component of working memory in this pattern of behavior. This model, along with a number of other related theoretical frameworks such the Global Workspace Model (Dehaene et al., 1998; Dehaene and Naccache, 2001) and the Contention Scheduling and Supervisory Attention Systems proposed by Norman and Shallice (1986) and Shallice and Burgess (1996), posit a form of competition between concurrently active goals that, within a limited-capacity system, serves to organize behavior. For many tasks, the relative strengths of environmental triggers for routine actions, and the value of the expected reward from an action, may be quite sufficient to produce coherent behavior in a relatively "automatic" fashion. A second level of general (as opposed to modalityor task-specific) control is also suggested, which is associated with conscious or effortful processing and that can endogenously adjust the "weight" of competing goals in accordance with environmental and internal factors. This is particularly associated with the function of a prefrontal or fronto-parietal network (Duncan, 2006). Data from human and animal lesion studies, as well as structural and functional brain imaging, converge on this matter at the broadest level (Milner, 1982; D'Esposito et al., 1995; Shallice and Burgess, 1996), though the specific roles of subregions of prefrontal cortex remains the subject of intense debate (Duncan and Owen, 2000; Stuss, 2006).

Executive functioning measurement is notoriously difficult due to the inherent differences between everyday situations that tax executive functions and the context of a typical neuropsychological assessment. There are well-documented reports of individuals with striking functional impairments performing within the expected range on traditional neuropsychological tests (Shallice and Burgess, 1991). Factors thought to contribute toward this discrepancy include the novelty of associated tasks, the degree of structure afforded by the respective settings, the clarity of relevant goals, and presence of distractions to name but a few (Silver, 2000; Emslie et al., 2003). The Behavioral Assessment of the Dysexecutive Syndrome (BADS; Wilson et al., 1996) was developed for adults with the particular intention to provide an ecologically valid assessment that captures the more elusive aspects of the dysexecutive syndrome frequently missed by traditional tests, whilst being informed by more contemporary neuropsychological models. It is now a widely-used test within the United Kingdom and there is good evidence for its validity (Burgess et al., 1998, 2006). The BADS battery detected significant differences between children with ADHD, those with Acquired Brain Injury and age and IQ matched participants (Hughes et al., 2013). Notwithstanding, Anderson (1998) critically reviewed EF measures in children and adolescents and observed the selection to be seriously lacking, with standardized batteries reported to neglect measures of EF, and with those tests available being of little interest to children, lacking appropriate normative data, and being difficult to interpret due to the involvement of lower-level cognitive skills that are themselves incompletely developed. Whilst this review is now somewhat dated, nevertheless the conclusions reached remain contemporary (Roy et al., 2015). In particular, Nyongesa et al. (2019) in a scoping review of 705 studies examining EF in adolescents from 2002-2017 observed that less than seven percent $(n=48)$ reported on the reliability and/or validity of EF measures employed which were limited to high income countries. This review underscored the importance of considering the psychometric properties of EF measures, given that the existing evidence remains limited.

With these above issues in mind, Emslie et al. (2003) developed the Behavioral Assessment of the Dysexecutive Syndrome for Children (BADS-C) to address the need for a reliable and valid assessment of executive functions that included child-friendly materials, standardized administration and scoring instructions as well as comprehensive norms. BADS-C battery consists of six subtests: the Playing Cards Test, the Water Test, the Key Search Test, Zoo Map Tests 1 and 2, and the Six Part Test. Emslie et al. (2003) reported that the battery has excellent inter-rater reliability for the majority of measures (0.91-1.0), with lower reliability (0.53) for only one measure, the number of perseverative errors on the Water test. Test re-test reliability was assessed after 34 weeks, and significant improvements in performance were found for the Playing Cards and Six Parts tests. In addition, all children obtained the maximum score on the Water test on second administration which is not unsurprising given the nature of the tasks (i.e., where novelty is a component) and short testing interval. Correlations between BADS-C scores and scores on the Strengths and Difficulties Questionnaire (SDQ) were also examined, with the pattern of results suggesting correspondence between behavioral performance and informant-rated problems in everyday life. Therefore, there is some evidence regarding the BADS-C validity. Engel-Yeger et al. (2009) employed BADS$\mathrm{C}$ in a normative sample of over 200 Arab-Israeli children and adolescents (aged 8-15). This study did not observed significant gender, familial socio-economic status nor parental level of education differences on the BADS-C. Notwithstanding 
as expected older children and adolescents performed better than younger children. As an aside, Willner et al. (2010) utilized the BADS-C as well as Cambridge Executive Functioning Assessment (CEFA) to assess EF in forty adults with mild to moderate learning disability. This study found that BADS-C scores were much lower in their sample than those observed in the BADSC normative sample. More recently, Roy et al. (2015) utilizing a French version of BADS-C in a group of 120 children (aged 712) showed age but not gender based developmental trajectories whilst simultaneously observing weak correlations between BADS-C scores, IQ and parental education. Accordingly, further BADS-C investigations might be useful to aid clinicians and researchers in the interpretation of their results within child and adolescent samples. Hence, this paper reports results from four relevant secondary analyses extracted from the BADS$C$ standardization sample. These analyses relate to the factor structure of the BADS-C and its accompanying questionnaire, the Dysexecutive Questionnaire for Children (DEX-C), which were intended to inform their construct validity; and analyses of the associations between scores on these measures and everyday difficulties as measured by the SDQ, and a comparison of the BADS-C performance of children showing everyday difficulties and those not showing such difficulties, which were intended to examine construct, convergent and to a lesser degree the predictive validity of the BADS-C.

\section{MATERIALS AND METHODS}

\section{Participants}

All participants were recruited on the basis of multi-center ethics approval granted by Cambridge Local Research Ethics Committee (LREC). The majority of participants in this study were recruited from schools in the east of England (United Kingdom). Letters explaining the project and asking for consent to participate were sent to the parents of all pupils in the relevant age groups (8-16 years) at these schools. Positive responses ranged from 40 to 95 percent, being consistently high in the primary schools and declining with increasing age in the secondary schools. A further 30 or so children who had taken part in a previous, unrelated research project were recruited on an individual basis.

After approximately 230 children had been tested, the mean estimated IQ for each age group was calculated using the Basic Reading test of the Wechsler Objective Reading Dimensions test (WORD; Wechsler, 1993). The majority of participants fell into the "average" ability range, so to ensure the extremes were not under-represented, subsequent recruitment was targeted at specific age and ability levels. Head teachers of a further group of schools agreed to recruit on this basis. In total, 260 individuals were assessed, though data from four children falling within the intellectual disability range (estimated IQ of $\leq 70$ ) were excluded. Suffice to state, access to the full data-set is available on request to the first author.

The final normative group comprised 256 children (114 males, 142 females) across eight age bands from 8 years 0 months and 15 years 11 months. Chi squared tests confirmed that there were no systematic differences in the number of participants in each age band $\left[\chi^{2} d f(7)=2.75, p=0.91\right.$; range $\left.=29-40\right]$, and that the numerical difference in the proportion of males to females was not statistically significant $\left[\chi^{2} d f(7)=3.06, p=0.08\right]$. The mean estimated IQ of the group as a whole was 100.5 $(\mathrm{SD}=12.7)$, and a boxplot showed that scores were normally distributed. Univariate ANOVA showed that estimated IQ did not vary significantly as a function of age group $[F(1,7)=2.01$, $p=0.055]$, or sex $[F(1,1)=0.098, p=0.755]$, and nor was there an interaction $[F(1,7)=0.923, p=0.489]$. Table 1 provides further details of participants and estimated IQ according to age group and gender.

ANOVA showed no evidence of a systematic variation in estimated IQ by age band or sex. Notwithstanding Figure 1 illustrates the 11-year old age group had a somewhat reduced mean IQ in relation to other age bands due to the presence of a greater proportion of children with estimated IQs below 90 . However, the difference did not reach statistical significance and as all IQs were above the cut off which may indicate intellectual disability (estimated IQ of $\leq 70$ ), no further cases were excluded from the analysis.

\section{Procedure}

Each participant was test individually in a quiet room, either at their school or a research institution. Participants completed the BADS-C and the Basic Reading Test from the WORD (Wechsler, 1993). The teachers of all primary-school-age children and the parents of all secondary-school-age children and adolescents were asked to complete two questionnaires, the DEX-C (Emslie et al., 2003) and the SDQ (Goodman, 1997).

\section{Measures}

\section{The Behavioral Assessment of the Dysexecutive Syndrome for Children (Emslie et al., 2003)}

The BADS-C consists of six subtests: the Playing Cards Test, the Water Test, the Key Search Test, Zoo Map Tests 1 and 2, and the Six Part Test. The Playing Cards Test requires children to establish and then update a pattern of responding. The child is shown a series of pictures of playing cards, and is asked to give verbal responses according to one "easy" rule (say "yes" to red and "no" to black), and then according to a new, more complex, rule (say "yes" if the card is the same color as the one before it, and "no" if it is not). This test constitutes a measure of cognitive flexibility. Scores are derived on the basis of time taken and uncorrected errors made.

The Water Test is a novel problem-solving task. Children are presented with an array of items and asked to find a solution to a practical problem according to a set of rules (to retrieve a cork from a tube using any item from the array including an empty container, a beaker of water with a plastic lid, and a wire hook, but without touching the lid with their fingers). A prompt detailing the first step (remove the lid with the wire) may be given if a child makes perseverative errors or has not completed the first step within $75 \mathrm{~s}$. Scores are derived from the number of stages completed correctly, and the time taken. 
TABLE 1 | Participants and estimated IQ by age and gender.

\begin{tabular}{|c|c|c|c|c|c|c|}
\hline \multirow[t]{2}{*}{ Age in years } & \multirow[t]{2}{*}{ Sex } & \multirow[t]{2}{*}{$N$} & \multicolumn{4}{|c|}{ Estimated IQ } \\
\hline & & & Mean & SD & Minimum & Maximum \\
\hline \multirow[t]{3}{*}{8} & Female & 24 & 102.67 & 14.156 & 72 & 126 \\
\hline & Male & 16 & 104.56 & 12.431 & 82 & 122 \\
\hline & Total & 40 & 103.43 & 13.361 & 72 & 126 \\
\hline \multirow[t]{3}{*}{9} & Female & 24 & 104.33 & 11.970 & 83 & 127 \\
\hline & Male & 10 & 102.40 & 14.909 & 78 & 120 \\
\hline & Total & 34 & 103.76 & 12.699 & 78 & 127 \\
\hline \multirow[t]{3}{*}{10} & Female & 16 & 105.87 & 8.374 & 90 & 122 \\
\hline & Male & 15 & 97.73 & 11.640 & 78 & 120 \\
\hline & Total & 31 & 101.94 & 10.742 & 78 & 122 \\
\hline \multirow[t]{3}{*}{11} & Female & 13 & 93.46 & 14.069 & 73 & 117 \\
\hline & Male & 17 & 93.88 & 14.044 & 71 & 113 \\
\hline & Total & 30 & 93.70 & 13.812 & 71 & 117 \\
\hline \multirow[t]{3}{*}{12} & Female & 17 & 97.94 & 12.487 & 78 & 118 \\
\hline & Male & 14 & 100.57 & 16.018 & 71 & 122 \\
\hline & Total & 31 & 99.13 & 14.004 & 71 & 122 \\
\hline \multirow[t]{3}{*}{13} & Female & 17 & 98.24 & 13.184 & 75 & 117 \\
\hline & Male & 13 & 99.62 & 9.614 & 87 & 114 \\
\hline & Total & 30 & 98.83 & 11.603 & 75 & 117 \\
\hline \multirow[t]{3}{*}{14} & Female & 15 & 97.93 & 12.092 & 81 & 117 \\
\hline & Male & 14 & 102.86 & 10.257 & 85 & 118 \\
\hline & Total & 29 & 100.31 & 11.324 & 81 & 118 \\
\hline \multirow[t]{3}{*}{15} & Female & 16 & 104.38 & 10.282 & 75 & 115 \\
\hline & Male & 15 & 99.20 & 12.405 & 77 & 114 \\
\hline & Total & 31 & 101.87 & 11.471 & 75 & 115 \\
\hline \multirow[t]{3}{*}{ Total } & Female & 142 & 101.06 & 12.577 & 72 & 127 \\
\hline & Male & 114 & 99.91 & 12.820 & 71 & 122 \\
\hline & Total & 256 & 100.55 & 12.674 & 71 & 127 \\
\hline
\end{tabular}

The Key Search Test is a measure of planning ability that involves presenting the child with an A4 sheet of paper with a large square printed on it, that they are asked to imagine represents a large field in which they have lost a key. The child is asked to draw a line to show how they would go about finding the key. Scores are derived on the basis of overall quality of the plan, according to set criteria detailed in the manual.

The Zoo Map tests also measure planning. The child is shown a map of a zoo and asked, in version 1 of the test, to plan a route around it so that they may see a prescribed set of attractions, according to particular rules (e.g., not using particular walkways more than once, and with specified start and end points). Version 2 of the test is a measure of following instructions, the child is asked to follow a written plan of the route. Performance on the low-demand Part 2 facilitates interpretation of Part 1, in terms of excluding comprehension problems as a basis for mistakes on Part 1.

The Six Parts test is a multifaceted test of planning, scheduling and performance monitoring. Children are given three simple tasks to complete (sorting, simple arithmetic, and picture naming), each with two versions. They are given $5 \mathrm{~min}$ in which to attempt something from each task, according to the rule that they must not follow one version of a task with the other version of the same task. A clock and written summary of the rules is provided. Scores are derived from the number of tasks completed and rules broken.

In the published test, raw scores were converted to scaled scores. Scaled scores for all six subtests take into account the strong impact of age on test performance (as expected, there were significant linear trends for all raw scores). For all but two subtests, Key Search and Zoo Map 2, scaled scores also take into account estimated IQ within three bands, because estimated ability was found to have a moderate impact upon performance on these tasks. Further detail on the derivation of scaled scores can be found in the test manual (Emslie et al., 2003).

\section{Basic Reading Test From WORD (Wechsler, 1993)}

This brief test assesses decoding of letters and words, in younger and/or less able children, and progresses to reading aloud single words of increasing complexity. The average correlations between the BRT and verbal and full-scale IQ was calculated with a Fisher's $Z$ transformation on the $r$-values quoted in the WORD manual for each year group from 8 to 16 years. The average correlation between BRT and WISC-III verbal IQ was 0.57 and between BRT and WISC-III full-scale IQ was 0.52. This indicates that there is a reasonable association between BADS-C performance and general intellectual ability. 


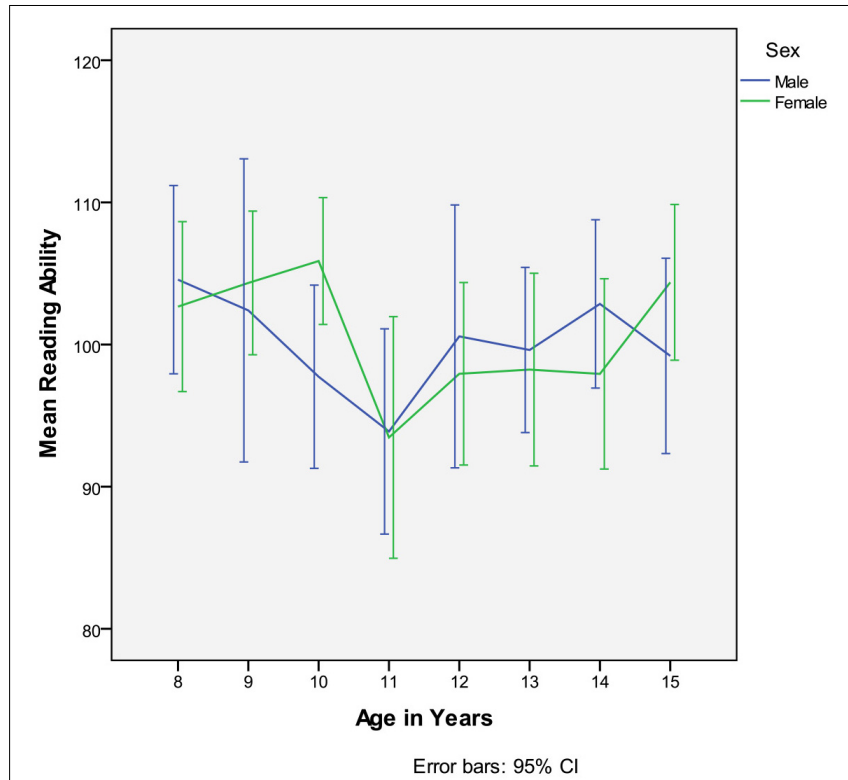

FIGURE 1 | Estimated IQ by age group and sex.

\section{The Dysexecutive Questionnaire for Children (Emslie et al., 2003)}

This questionnaire, which forms a supplement to the BADSC battery, consists of 20 items related to cognitive, social and behavioral components of the dysexecutive syndrome, with each items rated on a 5-point Likert scale with the anchor points of "rarely" to "very often." The DEX-C should be completed by someone who knows the child well, such as a parent, other family member, teacher or care worker. During BADS-C test development, teachers of primary school aged children completed DEX-C. As such teachers of primary school aged children spend significant more time with pupils than their high school equivalents. Whereas, for those in secondary level education, parents completed DEX-C. This process was also deployed for the second questionnaire measure.

\section{The Strengths and Difficulties Questionnaire (Goodman, 1997)}

This widely-used measure comprises 25 items, with 5 items in each of the following domains: emotional symptoms, conduct problems, hyperactivity/inattention, peer relationship problems, and pro-social behavior. There are versions for ratings of teachers and parents. Scores from the first four domains are grouped to form a "total difficulties score." In this study, teacher ratings were obtained for children under 11 years, and parent ratings for children older than 11 years. Of note, Stone et al. (2010) who reviewed 48 studies among children from age 4-12 years observed satisfactory internal consistency, test-retest reliability and inter-rater agreement for both parent and teacher versions. Reliability for the teacher version was noted to be somewhat stronger than the parent version. Of the studies examining construct validity, most yielded a
TABLE 2 | Factor loadings and communalities based on a principal components analysis with Varimax rotation for BADS-C subtests.

\begin{tabular}{lccc}
\hline & 1: Monitoring & 2: Abstraction & Communalities \\
\hline Playing cards & 0.632 & 0.176 & 0.43 \\
Water & -0.009 & 0.758 & 0.57 \\
Key search & 0.073 & 0.729 & 0.54 \\
Zoo map 1 & 0.566 & 0.055 & 0.32 \\
Zoo map 2 & 0.710 & -0.016 & 0.51 \\
Six parts & 0.435 & -0.053 & 0.19 \\
\hline
\end{tabular}

five-factor structure for the SDQ. However, more recently, Cheng et al. (2018) in a study involving children aged 611 years of age across seven European countries excluding United Kingdom observed low to moderate parent-teacher agreement across the five SDQ subscales and helpfully offered a number of explanatory factors to account for informant disagreement.

\section{RESULTS}

\section{Analysis I: Factor Structure of the BADS-C}

The BADS and BADS-C are intended to encompass a variety of components of the "dysexecutive" syndrome, including planning, strategic behavior, time management, cognitive flexibility, and abstract thinking. It is therefore likely that the battery consists of latent subscales reflecting different $\mathrm{EF}$ domains. To investigate this issue scaled scores of the six BADS-C subtests were entered into a factor analysis with extraction by the Principal Components method and using Varimax rotation. Table 2 shows a two-factor solution with the first component having an Eigenvalue of 1.42 after rotation and explaining $24.8 \%$ of variance, and the second having an Eigenvalue of 1.14, explaining $19.1 \%$ of variance. The first component loaded on Playing Cards, Zoo Map 1, Zoo Map 2, and to a lesser degree the Six Parts Test, whereas the second loaded on Water and Key Search tests only. These components have been labeled "monitoring" versus "abstraction" tasks, respectively. The communalities for each variable were above 0.3 , with the exception of the Six Parts Test. This could be a result of the measure being unreliable, or it measuring something different than other variables. Given the extensive empirical evaluation of the measure from which the Six Parts test was derived (Wilson et al., 1996) the latter seems more likely. In any case, it is unsurprising that neither component loads particularly strongly on this variable.

\section{Analysis II: Factor Structure of the DEX-C}

To investigate the latent structure of the DEX-C, all 20 questionnaire items were entered into a factor analysis with extraction by the Principal Components method using Varimax rotation. Communalities for these variable were all $>0.5$ indicating substantial shared variance. Table 3 illustrates the three-factor solution which explained $67 \%$ of the total variance. 
TABLE 3 | Rotated Component Matrix for DEX-C items showing strongest loading per item.

\begin{tabular}{|c|c|c|c|c|c|}
\hline \multirow[t]{2}{*}{ Item } & \multirow[t]{2}{*}{ Content } & \multicolumn{3}{|c|}{ Component } & \multirow[t]{2}{*}{ Communalities } \\
\hline & & Behavior & Cognition & Responsiveness & \\
\hline 1 & Abstract thinking problems & & 0.837 & & 0.720 \\
\hline 2 & Impulsivity & 0.701 & & & 0.649 \\
\hline 3 & Confabulation & 0.651 & & & 0.619 \\
\hline 4 & Planning problems & & 0.831 & & 0.791 \\
\hline 5 & Euphoria & 0.800 & & & 0.688 \\
\hline 6 & Temporal sequencing problems & & 0.790 & & 0.741 \\
\hline 7 & Lack of insight/social awareness & & 0.581 & & 0.683 \\
\hline 8 & Apathy/lack of drive & & & 0.808 & 0.743 \\
\hline 9 & Disinhibition & 0.735 & & & 0.635 \\
\hline 10 & Variable motivation & 0.729 & & & 0.648 \\
\hline 11 & Shallow affective responses & & & 0.684 & 0.496 \\
\hline 12 & Aggression & 0.675 & & & 0.667 \\
\hline 13 & Lack of concern & 0.750 & & & 0.724 \\
\hline 14 & Perseveration & 0.731 & & & 0.631 \\
\hline 15 & Restlessness-hyperkinesis & 0.785 & & & 0.684 \\
\hline 16 & Inability to inhibit responses & 0.826 & & & 0.773 \\
\hline 17 & Knowing-doing dissociation & 0.698 & & & 0.693 \\
\hline 18 & Distractibility & & 0.605 & & 0.661 \\
\hline 19 & Poor decision-making ability & & 0.657 & & 0.582 \\
\hline 20 & No concern for social rules & 0.701 & & & 0.659 \\
\hline
\end{tabular}

After rotation, the first component had an Eigenvalue of 7.3, explaining $36.5 \%$ of the variance, the second an Eigenvalue of 4.16 , explaining $20.8 \%$ of variance, and the third of 2.04, explaining $10.2 \%$ of the variance. Before labeling the components, the correlation matrix was examined with only the strongest loading for each item remaining (i.e., one component for each item). The domains addressed by each DEX item were then added to the matrix to facilitate the identification of themes within each component, and the components were thus labeled "behavior," "cognition," and "responsiveness." This does not follow the factor structure previously identified by Burgess et al. for the DEX questionnaire in adults (inhibition, intentionality, and executive memory), but is broadly consistent with Stuss and Benson's (1984) delineation of emotional/personality, motivational, behavioral, and cognitive aspects of the dysexecutive syndrome which strongly influenced BADS-C development.

\section{Analysis III: Relationship Between BADS-C Subtest Performance and Indices of Everyday Functioning}

The BADS-C manual reported significant correlations between BADS-C total score and all indices from the SDQ problemfocussed sub-scales and these analyses are not repeated here. However, the relationships between the newly identified variables and reports of everyday function are presented in Table 4 below. From the table, there are moderate correlations between the DEX-C factors and SDQ subscales, and smaller but non-zero correlations between BADS-C factors and SDQ subscale and total scores (which are not trivial considering the difference in measuring child behavior directly versus obtaining informant ratings).

To examine the value of the BADS-C subtests in predicting problems in everyday life, the six BADS-C subtest scaled scores were entered into a stepwise multiple regression on the dependent variable of SDQ total difficulties score. A model based on the Six Parts and Key Search scores was found to predict everyday problems, however, the model accounted for only $8 \%$ of the variance $\left[R^{2 a d j}=0.08, F(2,221)=10.40\right.$, and $p<0.001$; Six Parts $\beta=-0.229, p<0.001$; and Key Search $\beta=-0.176$, $p=0.007]$. Repeating this analysis using the Factor Analysisderived scores for Abstraction, Monitoring, and Six Parts tests resulted in another significant model consisting of Abstraction and Six Parts variables, which accounted for $7.4 \%$ of the variance $\left[R^{2 a d j}=0.07, F(2,221)=9.776\right.$, and $p<0.001$; Six Parts $\beta=-0.221$, $p<0.001$; and Abstraction $\beta=-0.163, p=0.013$.

To investigate the power of BADS-C subscale scores to predict DEX-C scores, the above analyses was repeated on the dependent variable of DEX-C total scores. Likewise using the six subtest scores, a model based on the Six Parts and Key Search scores was significant but accounted for only $4 \%$ of the variance $\left[R^{2 a d j}=0.04, F(2,222)=6.08\right.$, and $p=0.003$; Six Parts $\beta=-$ $0.158, p<0.017$; and Key Search $\beta=-0.159, p=0.016]$. The equivalent analysis using the factor analysis-derived scores was significant only with the Six Parts score accounting for $2 \%$ of the variance $\left[R^{2 a d j}=0.02, F(1,222)=6.15\right.$, and $p=0.014 ; \beta=-0.165$, $p<0.014]$.

In summary, these statistically significant regression models indicate that there is a robust relationship between BADS-C subtest scores and indices of everyday functioning, and yields evidence that the measure has construct validity. However, 
TABLE 4 | Spearman's Correlations between BADS-C and SDQ subscale scores, and between DEX-C factors and SDQ subscale scores.

\begin{tabular}{|c|c|c|c|c|c|c|c|}
\hline & & DEX-C Beh. & DEX-C Cog. & DEX-C Resp. & BADS-C monitor & BADS-C abstract & BADS-C six parts \\
\hline \multirow[t]{3}{*}{ Prosocial } & $\mathrm{R}$ & $-0.398^{\star \star}$ & $-0.270^{\star \star}$ & $-0.353^{\star \star}$ & 0.067 & 0.067 & 0.066 \\
\hline & $P$ & 0.000 & 0.000 & 0.000 & 0.326 & 0.321 & 0.327 \\
\hline & $N$ & 219 & 219 & 219 & 220 & 220 & 220 \\
\hline \multirow[t]{3}{*}{ Emotional symptoms } & $\mathrm{R}$ & $0.327^{\star \star}$ & $0.315^{\star \star}$ & $0.175^{\star \star}$ & $-0.166^{*}$ & $-0.137^{\star}$ & $-0.219^{\star \star}$ \\
\hline & $\mathrm{P}$ & 0.000 & 0.000 & 0.010 & 0.014 & 0.043 & 0.001 \\
\hline & $N$ & 217 & 217 & 217 & 218 & 218 & 218 \\
\hline \multirow[t]{3}{*}{ Conduct Problems } & $\mathrm{R}$ & $0.647^{\star \star}$ & 0.131 & $0.282^{\star \star}$ & -0.131 & -0.080 & $-0.135^{\star}$ \\
\hline & $\mathrm{P}$ & 0.000 & 0.054 & 0.000 & 0.053 & 0.238 & 0.046 \\
\hline & $N$ & 217 & 217 & 217 & 218 & 218 & 218 \\
\hline \multirow[t]{3}{*}{ Hyperactivity } & $\mathrm{R}$ & $0.626^{\star \star}$ & $0.458^{\star \star}$ & 0.069 & $-0.167^{\star}$ & -0.122 & $-0.176^{\star \star}$ \\
\hline & $\mathrm{P}$ & 0.000 & 0.000 & 0.312 & 0.014 & 0.073 & 0.010 \\
\hline & $\mathrm{N}$ & 214 & 214 & 214 & 215 & 215 & 215 \\
\hline \multirow[t]{3}{*}{ Peer Problems } & $\mathrm{R}$ & $0.327^{\star \star}$ & $0.243^{\star \star}$ & $0.273^{\star \star}$ & -0.110 & $-0.135^{\star}$ & $-0.227^{\star \star}$ \\
\hline & $\mathrm{P}$ & 0.000 & 0.000 & 0.000 & 0.107 & 0.046 & 0.001 \\
\hline & $\mathrm{N}$ & 216 & 216 & 216 & 217 & 217 & 217 \\
\hline \multirow[t]{3}{*}{ Total Difficulties } & $\mathrm{R}$ & $0.623^{\star \star}$ & $0.395^{\star \star}$ & $0.244^{\star \star}$ & $-0.183^{\star \star}$ & $-0.155^{\star}$ & $-0.236^{\star \star}$ \\
\hline & $P$ & 0.000 & 0.000 & 0.000 & 0.006 & 0.021 & 0.000 \\
\hline & $N$ & 219 & 219 & 219 & 222 & 222 & 222 \\
\hline
\end{tabular}

* refers to significant and **highly significant.

the small proportion of variance explained by each model indicates that BADS-C scores would not be particularly useful in predicting everyday problems within the general population. Nevertheless, these modest relationships are of interest given the control sample includes children exhibiting few if any EF difficulties all of whom are in receipt of normal state education provision.

\section{Analysis IV: Comparing the BADS-C Performance of Children With Low and High SDQ Scores}

To further examine the relationship between BADS-C performance and everyday functioning, BADS-C scores of children falling in the lower and upper quartiles for SDQ total difficulties were compared. The median score on the SDQ total difficulties scale was 6 (mean 7.7, SD 6.6, range $0-34,25$ th percentile $=3$, and 75 th percentile $=11$ ). The "Low SDQ" group consequently comprised 72 children, and the "high SDQ" group included 62 children (the numbers are not equivalent as different numbers of children obtaining the criterion scores).

As Table 5 illustrates there was significant gender difference between the "low SDQ" and "high SDQ" groups $\left(\chi^{2}=4.81\right.$, $p=0.037$ ), with the low SDQ group containing a disproportionate number of girls. There was also a statistically significant 10 -point difference in estimated IQ between the groups $[t(132)=5.22$, $p<0.001]$.

A MANOVA was therefore conducted on the BADS-C subtest scores by SDQ score group, with estimated IQ included as a covariate $^{1}$. The multivariate effect was significant $F(6,126)=4.4$,

${ }^{1}$ Though the majority of age-scaled scores are also adjusted for approximate IQ, Key Search and Zoo Map 2 do not, hence IQ as a co-variate in this analysis. $p<0.001, \eta p^{2}=0.173$, a large effect. Between-subjects effects for the six subtests revealed significant differences between high and low SDQ groups with a small-medium effect size for Key Search $\left[F(1,31)=7.4, p=0.007\right.$, and $\left.\eta p^{2}=0.053\right)$ and Zoo Map $1\left[F(1,31)=5.72, p=0.018\right.$, and $\left.\eta p^{2}=0.042\right]$, and a mediumlarge effect size for the Six Parts test $[F(6,126)=4.39, p<0.001$, and $\left.\eta p^{2}=0.173\right]$. Table 6 and Figure 2 provides a summary of these comparisons.

The equivalent analysis was also conducted on the factor scores of the DEX-C (abstraction, monitoring, and six parts). The multivariate effect was significant $[F(3,129)=6.15, p=0.001$, and $\left.\eta p^{2}=0.125\right]$, as were the between subjects tests of the factor scores, with a medium-large effect for six elements $\left[F(1,131)=13.39, p<0.001\right.$, and $\left.\eta p^{2}=0.093\right]$ and smallmedium effect for both monitoring $[F(1,131)=6.171, p<0.011$, and $\left.\eta p^{2}=0.04\right]$ and abstraction $[F(1,131)=4.20, p<0.042$, and $\left.\eta p^{2}=0.031\right]$ scores. There was also statistically significant difference between the two groups on DEX total scores and factor scores but as this is expected given the concordance in response format and overlap in some items of the two questionnaires the results are not presented in full.

TABLE 5 | Gender and IQ distributions in groups obtaining low and high SDQ scores.

\begin{tabular}{llrrrrr}
\hline & & N & Mean & SD & Min & Max \\
\hline Low SDQ & Male & 27 & 106.41 & 9.605 & 78 & 120 \\
& Female & 45 & 105.47 & 10.778 & 75 & 127 \\
& Total & 72 & 105.82 & 10.295 & 75 & 127 \\
High SDQ & Male & 35 & 95.60 & 12.816 & 71 & 121 \\
& Female & 27 & 94.52 & 14.273 & 72 & 126 \\
& Total & 62 & 95.13 & 13.367 & 71 & 126
\end{tabular}




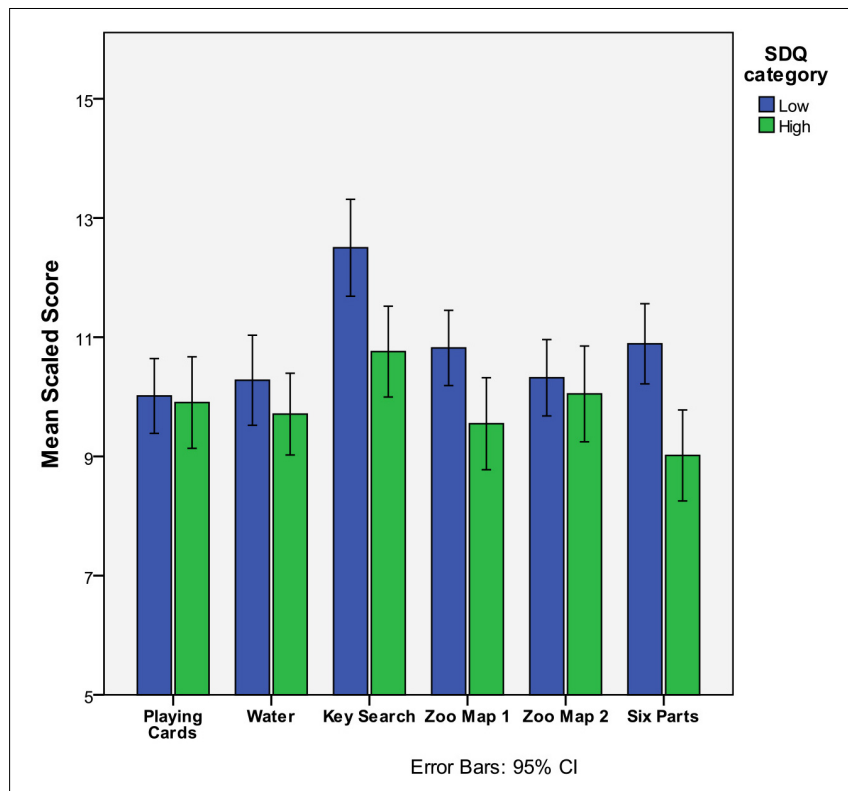

FIGURE 2 | Bar chart of BADS-C subtest Scaled scores according to SDQ score categorization. The error bars indicate 95\% Confidence Intervals, and illustrate significant differences in performance on Key Search, Zoo Map 1, and Six Parts tests only.

\section{DISCUSSION}

In summary, this study observed that the BADS-C has a two factor structure comprising monitoring and abstraction processes. The monitoring factor loads most strongly on Playing Cards and Zoo Map tasks, whereas the abstraction factor loaded on the Key Search and Water tasks. The Six Parts task did not load strongly on either factor. Secondly, the DEX-C questionnaire has a three-factor structure considered to represent behavioral and cognitive expressions of the dysexecutive syndrome, along with a weaker factor associated with aspects of social and emotional responsiveness. Thirdly, a consistent pattern of low-moderate correlations between BADS-C and DEX-C scores and SDQ scores, an established and widely used measure in children and young people was observed. Finally, a significant difference in the BADS-C performance of children and adolescents from the general population categorized as low ( $\leq 25$ th percentile) or high ( $\geq 75$ th percentile) on the SDQ total difficulties scale, even when the estimated IQ difference between the two groups is notable. This observation holds for the BADS-C total score as well as several individual subtests.

On the basis of these results, it seems reasonable to conclude that BADS-C is a valid EF measure among children and adolescents aged between 8 and 16 years. Given the limited evidence of psychometric validity of EF measures in widespread use (Nyongesa et al., 2019), this observation is of particular note. In addition, factor analysis indicates that the measures map onto established theoretical conceptualizations of the executive functions, whereas the third and fourth main findings indicate that the measure is sensitive to everyday difficulties that can be experienced by children with executive dysfunction (i.e., problems with conduct, hyperactivity, peer relationships, and emotional experience and regulation). Notwithstanding the regression models based upon BADS-C scores (either total score, or those derived from the factor analysis) were significant, they only accounted for a small amount $(<10 \%)$ of the variance in everyday functioning. Though this means that BADS-C scores alone are unlikely to be useful in predicting the occurrence of everyday difficulties, this finding must be interpreted in the light of the following considerations. Firstly, the SDQ, though the best available screening measure for these purposes, addresses a broad range of domains, and as such includes many symptoms that would not be expected to relate to executive functions (e.g., particularly emotional subscale items such as "often complains of headaches, stomach-aches or sickness," and "many fears, easily scared"). Secondly, there are obviously many biological, social and psychological factors that influence the expression of problems in the SDQ domains. Viewing the findings from this broad context, that performance on a "snapshot" test of EF accounts for any variance in reported

TABLE 6 | BADS-C subtest scores according to SDQ categorization, and the statistical comparisons.

\begin{tabular}{|c|c|c|c|c|c|c|}
\hline & SDQ & Mean & SD & Comparison & Significance & Effect size \\
\hline & High & 9.90 & 3.023 & & & \\
\hline & High & 9.71 & 2.700 & & & \\
\hline \multirow[t]{2}{*}{ Key search } & Low & 12.50 & 3.460 & $F(1,31)=7.389$ & $p=0.007$ & $\eta p^{2}=0.053$ \\
\hline & High & 10.76 & 3.001 & & & (small-med) \\
\hline & High & 9.55 & 3.039 & & & (small-med) \\
\hline \multirow[t]{2}{*}{ Zoo map 2} & Low & 10.32 & 2.726 & $F(1,31)=0.721$ & $p=0.398$ & $\eta p^{2}=0.005$ \\
\hline & High & 10.05 & 3.164 & & & \\
\hline \multirow[t]{2}{*}{ Six part } & Low & 10.89 & 2.861 & $F(1,31)=13.391$ & $p=0.001$ & $\eta p^{2}=0.093$ \\
\hline & High & 9.02 & 3.005 & & & (med-large) \\
\hline CBADS total & Low & 64.82 & 7.78 & $F(6,126)=4.39$ & $p<0.001$ & $\eta p^{2}=0.173$ \\
\hline
\end{tabular}


everyday problems in a representative normative sample is noteworthy. This finding is supported by the subsequent analysis of children scoring in the upper and lower quartiles of the SDQ total difficulties scale.

The factor structures observed to underlie the BADS-C and DEX-C make intuitive sense in their separation between abstraction/monitoring and cognitive/behavioral aspects of executive level problems, respectively. Whilst they do not map completely onto any one theoretical model, the factors are broadly consistent with Stuss and Benson's (1984) description of deficits that arising from frontal lobe damage. Given the aims of the development of the BADS and DEX were to develop an ecologically valid and sensitive test of EF, this is an expected pattern of results. The DEX-C's factor structure deviated from that reported by Burgess et al. (1998) in relation to the DEX, who identified five factors namely inhibition, intentionality, executive memory, positive affect, and negative affect. However, Burgess et al. (1998) reported that the DEX was designed with four domains in mind, specifically emotion/personality, motivation, behavior and cognition. Whilst there is no straightforward correspondence with the currently identified structure, there is certainly a large degree of overlap. The discrepancies in the derived factor structure between the child and adult versions of the questionnaire may result from differences in the presentations of dysexecutive syndrome in adults versus children, or difference in the nature of executive "symptoms" in children from the general population rather than children presenting clinically with executive dysfunction.

The scores obtained from the factor analyses explained a higher proportion of the variance in SDQ total difficulties than the total scaled score, but this increase was not sufficient to warrant the development of a revised scoring system for the BADS-C. It is also unlikely that the scores could be used to predict the likelihood of everyday difficulties on an individual basis. However, the identification of this factor structure could aid the interpretation of obtained test results. If these factors are kept in mind when examining the profile of a child's scores, then this provides additional information upon which recommendations for rehabilitation and/or management strategies may be based. For example, structured problem-solving techniques could be useful for children with difficulties on tasks that make up the abstraction component, whereas time management strategies, checklists, reminders, and cueing devices might be of more value for children displaying difficulties on tests that tap into the monitoring factor. These findings add further support to use of the BADS-C in populations likely to present with executive level difficulties as exemplified in recent studies involving BADS-C in Portuguese children with ADHD (de Almeida

\section{REFERENCES}

Alvarez, J. A., and Emory, E. (2006). Executive function and the frontal lobes: a meta-analytic review. Neuropsychol. Rev. 16, 17-42. doi: 10.1007/s11065-0069002-x

Anderson, V. (1998). Assessing executive functions in children: biological, psychological, and developmental considerations. Neuropsychol. Rehabil. 8, 319-349. doi: 10.1080/713755568 et al., 2014), French young people with frontal lobe tumors (Longaud-Vales et al., 2016) as well as Italian children with Neurofibromatosis Type I (Riva et al., 2017) to name but some. In conclusion, the evidence presented here suggests that the BADS-C and DEX-C are valid EF measures in children and adolescents which chart age-related developmental trajectories and as such may be of utility in academic and clinical pediatric neuropsychology practice.

\section{DATA AVAILABILITY STATEMENT}

The original contributions presented in the study are included in the article/supplementary material, further inquiries can be directed to the corresponding author/s.

\section{ETHICS STATEMENT}

The studies involving human participants were reviewed and approved by NHS Cambridge Local Research Ethics Committee (LREC) Ethics Committee. Written informed consent to participate in this study was provided by the participants' legal guardian/next of kin.

\section{AUTHOR CONTRIBUTIONS}

JF: undertook a secondary analysis of test development data. JF and FW: contributed to the manuscript text equally. Both authors contributed to the article and approved the submitted version.

\section{FUNDING}

BADS-C development was partly supported through a NHS Eastern Region R + D project grant (HSR/0500/11) to Dr. Hazel Emslie (now retired) and Professor Barbara Wilson (now retired).

\section{ACKNOWLEDGMENTS}

The assistance of all the children, parents, teachers, and colleagues who participated or assisted in this study is gratefully acknowledged. The authors gratefully acknowledge the significant contribution and involvement of Dr. Hazel Emslie, Dr. Ian Nimmo-Smith and Professor Barbara Wilson to the development and standardisation of the Behavioural Assessment of the Dysexecutive Syndrome for Children (BADS-C).

Baddeley, A. D., and Wilson, B. A. (1988). Frontal amnesia and the dysexecutive syndrome. Brain Cogn. 7, 212-230. doi: 10.1016/0278-2626(88)90031-0

Barkley, R. A. (1997). Behavioral inhibition, sustained attention, and executive functions: constructing a unifying theory of ADHD. Psychol. Bull. 121, 65-94. doi: 10.1037/0033-2909.12 1.1 .65

Biederman, J., Monuteaux, M. C., Doyle, A. E., Seidman, L. J., Wilens, T. E., Ferrero, F., et al. (2004). Impact of executive function deficits and attention-deficit/ 
hyperactivity disorder (ADHD) on academic outcomes in children. J. Consult. Clin. Psychol. 72, 757-766. doi: 10.1037/0022-006X.72.5.757

Burgess, P. W., Alderman, N., Evans, J. J., Emslie, H., and Wilson, B. A. (1998). The ecological validity of tests of executive function. J. Int. Neuropsychol. Soc. 4, 547-558. doi: 10.1017/s1355617798466037

Burgess, P. W., Alderman, N., Forbes, C., Costello, A., Coates, L. M.-A., Dawson, D. R., et al. (2006). The case for the development and use of "ecologically valid" measures of executive function in experimental and clinical neuropsychology. J. Int. Neuropsychol. Soc. 12, 194-209. doi: 10.1017/S13556177060 60310

Cheng, S., Keyes, K. M., Bitfoi, A., Carta, M. G., Koc, C., Goelitz, D., et al. (2018). Understanding parent-teacher agreement of the strengths and difficulties questionnaire (SDQ): comparison across seven European countries. Int. J. Methods Psychiatr. Res. 27:e1589. doi: 10.1002/mpr. 1589

Chevignard, M., Catroppa, C., Galvin, J., and Anderson, V. (2010). Development and evaluation of an ecological task to assess executive functioning post childhood TBI: the children's cooking task. Brain Impair. 11, 125-143. doi: 10.1375/brim.11.2.125

Cornish, K. M., Turk, J., Wilding, J., Sudhalter, V., Munir, F., Kooy, F., et al. (2004). Annotation: deconstructing the attention deficit in fragile X syndrome: a developmental neuropsychological approach. J. Child Psychol. Psychiatry 45, 1042-1053. doi: 10.1111/j.1469-7610.2004.t01-1-00 297.x

de Almeida, R., Macedo, G., Lopes, E., and Monteiro, L. (2014). BADS-C instrument: an ecological perspective of the executive functions in children with attention deficit hyperactivity disorder. Acta Neuropsychol. 12, 293-303. doi: 10.5604/17307503.1124958

Dehaene, S., Kerszberg, M., and Changeux, J. P. (1998). A neuronal model of a global workspace in effortful cognitive tasks. Proc. Natl. Acad. Sci. U.S.A. 95, 14529-14534. doi: 10.1073/pnas.95.24.14529

Dehaene, S., and Naccache, L. (2001). Towards a cognitive neuroscience of consciousness: basic evidence and a workspace framework. Cognition 79, 1-37. doi: 10.1016/s0010-0277(00)00123-2

D’Esposito, M., Detre, J. A., Alsop, D. C., Shin, R. K., Atlas, S., and Grossman, M. (1995). The neural basis of the central executive system of working memory. Nature 378, 279-281. doi: 10.1038/378279a0

Diamond, A. (2013). Executive functions. Ann. Rev. Psychol. 64:135. doi: 10.1146/ annurev-psych-113011-143750

Duncan, J. (2006). EPS Mid-Career Award 2004: brain mechanisms of attention. Q. J. Exp. Psychol. 59, 2-27. doi: 10.1080/174702105002 60674

Duncan, J., and Owen, A. M. (2000). Common regions of the human frontal lobe recruited by diverse cognitive demands. Trends Neurosci. 23, 475-483. doi: 10.1016/s0166-2236(00)01633-7

Emslie, H., Wilson, F. C., Burden, V., Nimmo-Smith, I., and Wilson, B. A. (2003). The Behavioural Assessment of the Dysexecutive Syndrome for Children (BADS-C). Bury St Edmunds: Thames Valley Test Company.

Engel-Yeger, B., Josman, N., and Rosenblum, S. (2009). Behavioural assessment of the dysexecutive syndrome for children (BADS-C): an examination of construct validity. Neuropsychol. Rehabil. 19, 662-676. doi: 10.1080.096020108026 22730

Goodman, R. (1997). The strengths and difficulties questionnaire: a research note. J. Child Psychol. Psychiatry 38, 581-586. doi: 10.1111/j.1469-7610.1997. tb01545.x

Hill, E. L. (2004). Executive dysfunction in autism. Trends Cogn. Sci. 8, 26-32.

Hughes, A., Wilson, F. C., Trew, K., and Emslie, H. (2013). Detecting executive deficits in children with ADHD or acquired brain injury using the behavioural assessment of dysexecutive syndrome (BADS). Ir. J. Psychol. 34, 13-23. doi: $10.1080 / 03033910.2012 .754323$

Lanfranchi, S., Jerman, O., Dal Pont, E., Alberti, A., and Vianello, R. (2010). Executive function in adolescents with down syndrome. J. Intellect. Disabil. Res. 54, 308-319. doi: 10.1111/j.1365-2788.2010.01 262.x

Longaud-Vales, A., Chevignard, M., Dufour, C., Grill, J., Puget, S., Sainte-Rose, C., et al. (2016). Assessment of executive functioning in children and young adults treated for frontal lobe tumours using ecologically valid tests. Neuropsychol. Rehabil. 26, 558-583. doi: 10.1080/09602011.2015.1048253

Milner, B. (1982). Some cognitive effects of frontal-lobe lesions in man. Philos. Trans. R. Soc. Lond. Ser. B Biol. Sci. 298, 211-226. doi: 10.1098/rstb.1982. 0083

Norman, D. A., and Shallice, T. (1986). "Attention to action: willed and automatic control of behaviour," in Consciousness and Self-Regulation, eds R. J. Davidson, G. E. Schwartz, and D. Shapiro (New York, NY: Plenum Press).

Nyongesa, M. K., Ssewanyana, D., Mutua, A. M., Chongwo, G. S., Newton, C. R. J. C., and Abubakar, A. (2019). Assessing executive function in adolescence: a scoping review of existing measures and their psychometric robustness. Front. Psychol. 10:311. doi: 10.3389/fpsyg.2019. 00311

Parrish, J., Geary, E., Jones, J., Seth, R., Hermann, B., and Seidenberg, M. (2007). Executive functioning in childhood epilepsy: parent-report and cognitive assessment. Dev. Med. Child Neurol. 49, 412-416. doi: 10.1111/j.1469-8749. 2007.00412.x

Riggs, N. R., Jahromi, L. B., Razza, R. P., Dillworth-Bart, J. E., and Mueller, U. (2006). Executive function and the promotion of socio-emotional competence. J. Appl. Dev. Psychol. 27, 300-309. doi: 10.1016/j.appdev.2006. 04.002

Riva, D., Vago, C., Erbetta, A., Saletti, V., Espositio, S., Michelli, R., et al. (2017). The key search subtest of the behavioural assessment of dysexecutive syndrome in children (BADS-C) instrument reveals impaired planning without external constraints in children with neurofibromatosis type I. J. Child Neurol. 32, 387-396. doi: 10.1177/0883073816683322

Robinson, S., Goddard, L., Dritschel, B., Wisley, M., and Howlin, P. (2009). Executive functions in children with autism spectrum disorders. Brain Cogn. 71, 362-368. doi: 10.1016/j.bandc.2009.06.007

Roy, A., Allain, P., Roulin, J.-L., Fournet, N., and Le Gall, D. (2015). Ecological approach of executive functions using the behavioural assessment of dysexecutive syndrome for children (BADS-C): developmental and validity study. J. Clin. Exp. Neuropsychol. 37, 956-971. doi: 10.1080/13803395.2015. 1072138

Shallice, T., and Burgess, P. (1996). The domain of supervisory processes and temporal organization of behaviour. Philos. Trans. R. Soc. Lond. Ser. B Biol. Sci. 351, 1405-1411; discussion 1411-1412. doi: 10.1098/rstb.1996.0124

Shallice, T., and Burgess, P. W. (1991). "Higher-order cognitive impairments and frontal lobe lesions in man," in Frontal Lobe Function and Dysfunction, eds H. S Levin, H. M. Eisenberg, and A. L. Benton (New York, NY: Oxford University Press), 125-138.

Silver, C. H. (2000). Ecological validity of neuropsychological assessment in childhood traumatic brain injury. J. Head Trauma Rehabil. 15, 973-988. doi: 10.1097/00001199-200008000-00002

Slomine, B. S., Gerring, J. P., Grados, M. A., Vasa, R., Brady, K. D., Christensen, J. R., et al. (2002). Performance on measures of executive function following pediatric traumatic brain injury. Brain Injury 16, 759-772. doi: 10.1080/ 02699050210127286

Stone, L. L., Otten, R., Engels, R. C. M. E., Vermulst, A. A., and Janssens, J. M. A. M. (2010). Psychometric properties of the parent and teacher versions of the strengths and difficulties questionnaire for 4- to 12-year-olds: a review. Clin. Child Fam. Psychol. Rev. 13, 254-274. doi: 10.1007/s10567-010-0071-2

Stuss, D. T. (2006). Frontal lobes and attention: processes and networks, fractionation and integration. J. Int. Neuropsychol. Soc. 12, 261-271. doi: 10. 1017/S1355617706060358

Stuss, D. T., and Benson, D. F. (1984). Neuropsychological studies of the frontal lobes. Psychol. Bull. 95, 3-28. doi: 10.1037/0033-2909.95.1.3

Tonks, J., Yates, P., Frampton, I., Williams, W. H., Harris, D., and Slater, A. (2011). Resilience and the mediating effects of executive dysfunction after childhood brain injury: a comparison between children aged 9-15 years with brain injury and non-injured controls. Brain Injury 25, 870-881. doi: 10.3109/02699052. 2011.581641

Wechsler, D. (1993). Wechsler Objective Reading Dimensions. San Antonio, TX: The Psychological Corporation.

Welsh, M. C., and Pennington, B. F. (1988). Assessing frontal lobe functioning in children: views from developmental psychology. Dev. Neuropsychol. 4, 199-230. doi: $10.1080 / 87565648809540405$ 
Willcutt, E. G., Doyle, A. E., Nigg, J. T., Faraone, S. V., and Pennington, B. F. (2005). Validity of the executive function theory of attention-deficit/hyperactivity disorder: a meta-analytic review. Biol. Psychiatry 57, 1336-1346. doi: 10.1016/j. biopsych.2005

Willner, P., Bailey, R., Parry, R., and Dymond, S. (2010). Evaluation of executive functioning in people with intellecutal disabilities. J. Intellect. Disabil. Res. 54, 366-379. doi: 10.1111/j.1365-2788.2010.01249.x

Wilson, B. A., Evans, J. J., Alderman, N., Burgess, P. W., and Emslie, H. (1996). Behavioural Assessment of the Dysexecutive Syndrome. London: Pearson Assessment.
Conflict of Interest: The authors declare that the research was conducted in the absence of any commercial or financial relationships that could be construed as a potential conflict of interest.

Copyright (C) 2021 Fish and Wilson. This is an open-access article distributed under the terms of the Creative Commons Attribution License (CC BY). The use, distribution or reproduction in other forums is permitted, provided the original author(s) and the copyright owner(s) are credited and that the original publication in this journal is cited, in accordance with accepted academic practice. No use, distribution or reproduction is permitted which does not comply with these terms. 